\title{
PRAÇAS PUBLICAS NA CONTEMPORANEIDADE: HISTÓRIA, MULTIDÃO E IDENTIDADE
}

\author{
JOSÉ HORTA NUNES*
}

\begin{abstract}
RESUMO: Este trabalho efetua uma análise de discursos de organização das praças públicas no espaço urbano. A praça é considerada como um objeto discursivo, como um espaço simbólico e de significação, constituído pela linguagem e pelas práticas sociais em determinadas conjunturas históricas. São analisadas algumas das condições de produção dos discursos das praças contemporâneas. Em seguida, são apresentadas análises de algumas formas de discursos de praças, que envolvem a produção de imaginários da história, da multidão, das parcerias entre público e privado e da constituição de identidades institucionais, empresariais e comunitárias. Finalmente, opera-se o conceito de tópica cívica para se compreender a relação entre os discursos analisados. Palavras-chave: discurso, cidade, praça
\end{abstract}

RESUME: Ce travail présente une analise des discours d'organisation des places publiques dans l'espace urbain. La place est considerée comme un objet discursif, comme un espace symbolique et de signification, constitué par le langage et par les pratiques sociales dans certaines conjonctures historiques. D'abord, sont analisées les conditions de production des places contempoaraines, y inclus la production d'imaginaires de l'histoire, de la foule, des partenariats entre le public et le privé et de la constitution d'identités institutionnelles, d'entreprises et communautaires. Par fin, nous opérons le concept de «tópica cívica » pour comprendre le rapport entre les discours analisés.

Mots-clés : discours, ville, place

\section{INTRODUÇÃO}

Ao tomar a cidade como objeto de estudo, a Análise de Discurso constitui um lugar para se observar o urbano pelo viés da linguagem, do simbólico (ORLANDI, 2001, 2004). Inscreve-se dessa forma, ao lado dos campos de saber que se dedicam ao estudo da cidade, como o urbanismo, as ciências sociais, a história, a arquitetura e outros, trabalhando questões que perpassam essa região teórica a partir do dispositivo da Análise de Discurso. A especificidade do ponto de vista discursivo está em não tomar os sentidos da/sobre a cidade como evidentes e em analisar os seus processos de constituição. Estabelece-se, assim, uma escuta atenta aos discursos que aí se produzem e circulam. A cidade não é tomada enquanto espaço empírico, mas sim como constituído pelas práticas discursivas, pelas projeções imaginárias que elas mobilizam, pelas relações entre sujeitos e entre discursos no contexto urbano, pela historicidade dos sentidos, sempre levando em conta a espessura da língua.

Dessa perspectiva, ao se analisarem os diversos discursos que constituem o urbano: urbanísticos, administrativos, políticos, mediáticos, artísticos, históricos, ecológicos, etc.,

*UNESP/São José do Rio Preto 
explicita-se o modo como eles se constituem e se relacionam em determinadas conjunturas. A questão da linguagem muitas vezes é deixada de lado nas práticas de organização da cidade, com a predominância de um urbanismo tecnicista ou empirista. A introdução das pesquisas discursivas nesse campo faz com que a linguagem seja pensada em seu funcionamento na cidade, e com isso surgem certos objetos e questões de análise, diante da natureza das materialidades discursivas com as quais o analista se depara. Ir para a cidade, nesse sentido, significa estabelecer uma relação entre as ciências da linguagem e o real da cidade, colocando a Análise de Discurso como uma das ciências do urbano.

Dentre os objetos citadinos que se apresentam para análise, as praças são daqueles que marcam a formação das cidades e que se transformam frequentemente, acompanhando as mudanças conjunturais. A praça é comumente definida, em uma discursividade técnica, como um espaço público entre vias ou entre edifícios, tal como se nota nesta definição do dicionário Aurélio: "Lugar público cercado de edifícios" (FERREIRA, 1999), ou nesta outra de um dicionário especializado em urbanismo: "Logradouro público urbano, geralmente de forma retangular ou quadrada, delimitado por vias ou, algumas vezes, por edificações." (FERRARI, 2004). A isso se acrescentam finalidades como lazer e recreação e também a de reuniões públicas. Essas definições colocam em jogo, além da espacialidade física desse espaço, a dimensão das práticas e dos acontecimentos citadinos, ainda que de forma limitada a certas práticas como o lazer, a recreação e as reuniões. Podemos dizer que esses sentidos estão entre aqueles que se sedimentam, formando um imaginário corrente do que seja a praça. Mas ao mesmo tempo as práticas contemporâneas colocam em jogo outras materialidades e outras imagens que procuramos considerar.

Do ponto de vista discursivo, atenta-se para a praça vista como espaço simbólico e de significação, constituído pela linguagem, pelo discurso. Além disso, são observados os sujeitos que ali se constituem, bem como as materialidades que se apresentam: as situações, os objetos urbanos, as textualidades. É trabalhada também a dimensão dos acontecimentos e das práticas discursivas. As praças são observadas em sua singularidade e na relação entre elas, bem como em sua historicidade. Assim, não se parte de uma definição prévia, nem de sentidos a priori, mas procura-se observar os processos histórico-discursivos que se apresentam em cada situação.

Em trabalhos anteriores (NUNES, 2006a, 2006b), analisamos situações, textos e outras materialidades, como construções e objetos, em algumas praças. Isso nos permitiu entrar em contato com alguns dos discursos que se apresentam nessas situações, como o ecológico, o empresarial, o político, dentre outros. Uma vez feitas essas análises, no presente trabalho discutimos algumas questões que envolvem as praças em seu conjunto complexo, a fim de se explicitar regularidades, diferenças, contradições, complementaridades, etc. Observamos que as praças têm nas últimas décadas se diversificado significativamente, de modo que os discursos aí presentes também são vários. Esse fato vai de par com as transformações que afetam os sujeitos e os discursos urbanos, tal como procuraremos mostrar mais adiante. Temos em vista especificamente a posição de produção das praças, com a análise dos projetos de praça e da imagem que se faz de seu uso a partir dessa posição de organização, lembrando que, segundo E. Orlandi, "a cidade é organização, é injunção a trajetos, a vias, a repartições, a programas, a traçados e a tratados" (ORLANDI, 2001, p. 63). Compreender o modo de produção do imaginário das praças, da perspectiva de sua 
concepção, é também explicitar o seu uso projetado, com o qual os freqüentadores reais vão se confrontar, se identificar, sofrer exclusões, etc.

Para a análise, vamos tratar inicialmente das condições de produção das praças na contemporaneidade, para em seguida abordar algumas formas discursivas em circulação. Mostraremos os efeitos do modo como o Estado se apresenta na atualidade para a produção dos discursos das praças. Também observaremos a maneira como as formações sociais se constituem discursivamente, no jogo entre a unidade e a diversidade social, entre a multidão e a comunidade, entre a quantidade e a identidade. Levamos em conta ainda a relação entre formação social e espacialidade. Conforme vemos em Orlandi, e a partir de algumas reflexões de Paul Henry, podemos considerar o espaço como "enquadramento" das práticas que acontecem na cidade, o que leva a trabalhar com a forma e os meios materiais que constituem a cidade como espaço significativo: "enquadrar significa determinar o espaço de significação" (ORLANDI, 2010, p. 5-6). Consideramos, então, que o discurso das praças é enquadrado espacialmente e nessa medida o espaço e sua materialidade significam as relações sociais e as relações de sentido que aí se estabelecem.

\section{AS PRAÇAS NA CONTEMPORANEIDADE}

As praças na contemporaneidade são produzidas a partir de diferentes posições. Dentre elas está certamente a da administração pública, mas também as que remetem a diversas formas de "parceria" que envolvem a organização da cidade, na relação entre o público e privado: empresas, associações de bairro, movimentos sociais, escolas, moradores, etc. Além disso, os discursos das praças são direcionados a diferentes sujeitos ou grupos sociais. A diversidade e a heterogeneidade marcam esses discursos na atualidade

Uma incursão no discurso da arquitetura nos permite compreender algumas das condições de produção das praças contemporâneas. Segundo F. Robba (2003), nas duas últimas décadas do século XX uma série de mudanças projetuais e programáticas levaram à constituição de uma nova forma de modernidade: uma corrente projetual denominada contemporânea. Rompendo com alguns dos preceitos modernistas, os projetos contemporâneos são diversos e envolvem diferentes posturas. Algumas tendências se sobressaem: "Pós-Modernismo, Neo-Ecletismo, Ecologismo e outras tendências se configuram cada uma delas na sua diversidade e particularidade" (ROBBA, 2003, p. 12). Segundo o autor, quanto à forma, os projetos caracterizam-se por:

- revitalizações e restauros da imagem, o velho e o novo uso;

- reconfigurações e mudanças estruturais;

- colagem decorativa e irreverência;

- formalismo gráfico como contra ponto à praça ajardinada;

- cenarizações. (ROBBA, 2003, p. 12).

Quanto aos usos, são valorizados os seguintes aspectos: 
- introdução do uso comercial e de serviços (utilitarismo);

- direcionamento do uso para a passagem de pedestres e a circulação, com a criação de esplanadas e a revalorização da praça seca;

- criação de espaços multifuncionais e adaptáveis, que podem ser utilizados pela população das mais diversas formas. (ROBBA, 2003, p. 12).

Do ponto de vista discursivo, em que não se separa a forma do uso, podemos considerar que as transformações dos projetos de praça conformam diversas situações, espaços organizados, materialidades, projeções imaginárias dos sujeitos freqüentadores, das práticas e dos acontecimentos a ocorrerem nesses espaços. Interessa-nos na observação desses projetos mostrar de que modo se constituem discursivamente os sentidos de sociedade, diante da tensão entre a unidade e a diversidade que se apresentam na contemporaneidade. De um lado, as praças centrais e os grandes espaços livres multifuncionais trabalham os discursos fundadores e de globalização; de outro lado, praças menos centrais e periféricas tendem à fragmentação, com a construção de imaginários específicos, locais, comunitários, identitários. Assim, embora consideremos que a fragmentação é uma das marcas da contemporaneidade, ela é vista na relação com o que se tem chamado a "luta pelos lugares":

\footnotetext{
hoje há um outro modelo de representação social que é o horizontal: são as relações de lugares que prevalecem (Schaller, 2001). Aí o sujeito ou está dentro - e tem sua colocação, seu lugar - ou está fora. Não é mais o paradigma da inclusão/exclusão mas o da segregação. Não há a ilusão de possibilidade de ascenção vertical. Há a luta heróica do sujeito para ter um lugar qualquer (centro/ periferia). Domínio das relações individualistas, da fragmentação, da urgência.” (Orlandi, 2010, p. 13).
}

Sob a aparente "liberdade" atribuída aos projetos de praças atuais, vemos relações de força, diferenciações, exclusões, contradições, na medida em que o espaço citadino é dividido, segregado. Além disso, quando temos em vista o funcionamento do discurso, atentamos para certas materialidades específicas, como a escrita no espaço público e outras práticas simbólicas verbais e não-verbais, além das relações de interdiscursividade, da constituição dos sujeitos, da historicidade dos sentidos.

\section{MEMÓRIA E ATUALIDADE: PATRIMÔNIO HISTÓRICO E GLOBALIZAÇÃO}

Uma das tendências de projetos de praça na atualidade é a de produzir um discurso histórico, que busca atualizar uma memória dos discursos fundadores das praças, diante do risco de perda dessa memória, Assim, de um lado temos a fragmentação da sociedade, com a diversidade de grupos, de comunidades, de identidades; de outro, a reforma histórica, que confere uma certa unidade por meio da atualização de um discurso fundador.

Esse discurso de atualização da memória histórica, que mobiliza uma série de verbos como resgatar, reformar, recuperar, preservar, revitalizar etc. vai de par com uma tendência da globalização que consiste em identificar os "patrimônios históricos e culturais" das cidades e de fomentar atividades que visem à sua preservação. De acordo com J. Machado, “Em 1972, a Conferência Geral da UNESCO aprovou a Convenção para Proteção do 
Patrimônio Mundial Cultural e Natural com a missão de identificar e proteger sítios culturais e naturais considerados de excepcional valor universal em todo o mundo." (MACHADO, 2010, p. 13). Esse discurso universalizante determina uma série de políticas de planejamento urbano, interferindo no planejamento de praças em torno dos centros urbanos considerados como sítios históricos. O planejamento de tais sítios projeta uma imagem do sujeito turista, ao lado do morador local, de modo que turista e morador ficam identificados como representações organizadoras do espaço, das práticas e dos objetos urbanos:

Tudo aquilo que o turista deseja em matéria de conforto, segurança, informação, boa circulação viária, equipamentos públicos de boa qualidade, boas condições ambientais etc. é também o que cada morador precisa e deseja. Por isso, todo investimento destinado ao setor deve ter a perspectiva da apropriação local, deve ser duradouro, compatível com o uso cotidiano. Agindo assim, além de otimizar o uso de recursos públicos, se reduzirão os antagonismos eventualmente existentes entre esses dois segmentos. (MACHADO, 2010, p. 61).

A identificação simbólica do morador com o turista faz com que eles sejam indistintos nos discursos das praças. As conseqüências disso se notam na produção de materialidades textuais direcionadas imaginariamente a esses sujeitos. Os quiosques e as placas de informação, inseridos em algumas das reformas de praças atuais, são marcas do discurso direcionado ao turista. Na praça XV de Novembro, situada no bairro Cambuí, em Campinas, próximo à área central, uma reforma resultou na inserção de placas de informação direcionadas aos turistas. Nos textos notam-se indicações de lugares considerados de importância histórica e o convite para que os leitores visitem marcos de fundação e constituição da cidade.

Além disso, outras placas divulgam um discurso que atualiza os sentidos da "proclamação da República", com índices das práticas da chamada "nova história", selecionando-se como fatos dignos de memória sujeitos e acontecimentos cotidianos, situados localmente. Assim, o cenário da Proclamação da República não é o Rio de Janeiro, e nem traz a figura do Marechal Deodoro da Fonseca, mas sim a situação de Campinas, vista como local onde aconteceram eventos republicanos. As narrativas inseridas nas placas apontam para sujeitos locais, como um advogado republicano e abolicionista (Pedro de Magalhães) que participou dos movimentos republicanos, e o escravo Elesbão, na época enforcado e esquartejado no local A placa que constroi a imagem desse mártir injustiçado está fincada no mesmo lugar onde na época foi utilizada a forca.

É interessante notar nesse discurso de reforma de praça o funcionamento da escrita como objeto simbólico. Ao invés de monumentos e de construções, a praça conjuga um cenário ecológico, com um passeio rodeado de gramados, plantas e árvores, e a presença da escrita nas placas distribuídas nos caminhos. Os freqüentadores-leitores são interpelados assim pelas condições ambientais e pela indicação de um percurso cotidiano que liga a praça a seu entorno histórico por meio da linguagem. Segundo A. Filho, nos projetos que têm em vista a figura do turista e a perspectiva da comunicação global, joga fortemente a "legibilidade", que consiste em que "a forma projetada deve ser compreensível para os cidadãos, para haver convergências" (FILHO, 2008, p. 75-76). Assim, consideramos de nossa perspectiva que, por meio da espacialização da linguagem pelas placas turísticas, se constitui um imaginário do conhecimento didatizado das coisas públicas, da história e da cultura, tornando a praça legível, interpretável. 


\title{
AS PRAÇAS “SECAS”: VAZIO E AGLOMERAÇÃO
}

Ao lado das praças históricas, encontramos na atualidade, sobretudo em áreas centrais e outros locais de grande aglomeração, projetos de praça que se caracterizam pela produção de espaços vazios, a serem preenchidos pela multidão. Silêncio e quantidade são metaforizados nesses discursos do espaço. Havendo multidão, sobretudo nos grandes centros urbanos, os projetos apontam a necessidade de livre circulação e de encontros públicos de grande número e diversidade de sujeitos: em eventos, festas, comemorações, feiras, lazer etc.:

\begin{abstract}
Outra forma de utilização do espaço público comum nas praças contemporâneas contempla a circulação de pedestres. A necessidade de espaço para absorver a enorme quantidade de pessoas em trânsito na grande cidade sugere a elaboração de projetos que respondam a essa exigência e revaloriza a figura da praça seca, não muito comum nos últimos duzentos anos no Brasil.

Algumas praças e ruas transformam-se em pontos de convergência do fluxo de pedestres e necessitam de configurações formais que favoreçam e permitam a distribuição e a circulação dos transeuntes. Logradouros que recebem enormes quantidades de pessoas, como praças em áreas centrais, nos centros de bairros ou em locais onde foram instalados terminais de transporte coletivo urbano, apresentam traçados que devem acomodar o crescente movimento de pedestres. Muitas vezes, no lugar das áreas permeáveis e da vegetação, são propostas grandes áreas de pisos processados e esplanadas. As Praças do Ferreira, em Fortaleza, XV de Novembro, em Porto Alegre, Marechal Floriano e XV de Novembro, no Rio de Janeiro, são exemplos da aplicação de tal proposta. (ROBBA, 2003).
\end{abstract}

Em Campinas, as praças centrais do Largo do Rosário, entre as avenidas 13 de Maio e Campos Sales, e a praça Bento Quirino, na rua Barão de Jaguara, são duas praças reformadas que apresentam as características da "praça seca", com desenhos formais no amplo piso e espaço vazio para circulação de pedestres. O Largo do Rosário, tombado pelo CONDEFAT, passou por uma reforma em 1986, que retomou elementos do projeto de 1934, ao mesmo tempo em que desobstruiu o local de marquises e deixou espaço livre para pedestres e para a realização de feiras e eventos. Também a praça Bento Quirino, em sua reforma, abriu espaço para os pedestres e abriga feiras de artesanato e outros eventos. Comparando as imagens da mesma praça, nos anos 20, nota-se a retirada de um jardim contemplativo e a inserção de piso amplo sem obstáculos, com estreitas fileiras de árvores às margens.

Outra praça aos moldes da praça "seca", desta vez com dimensão mais ampla, é a Praça Arautos da Paz, localizada próxima à Lagoa do Taquaral (Parque Portugal). Essa praça, construída em 2001, é um grande espaço aberto onde ocorrem eventos, festas, espetáculos de circo, e que conta também com área verde recém-plantada e espaço para caminhadas. Destinada a abrigar grandes aglomerações, ela ganhou configuração de praça de lazer, assim como os parques que estão em seu entorno (Parque Portugal e Lago do Café).

Ao analisar as práticas de intervenção em centros urbanos, Castilho e Vargas afirmam que:

Diferentemente de outros períodos, em que havia o predomínio de grandes obras viárias, estações, centros cívicos e mesmo equipamentos sociais dispersos pela cidade, a ênfase, hoje, encontra-se 
no embelezamento dos espaços públicos de alta visibilidade, por meio de novas técnicas de comunicação e marketing, facilitando a reunião de multidões para as mais diversas formas de manifestações populares e cívicas: eventos ao ar livre transmitidos amplamente pela mídia e em busca de legitimação e aprovação política.” (CASTILHO \& VARGAS, 2009, p. 275-276)

As praças secas, ao abrigarem as multidões, inscrevem-se no calendário dos acontecimentos urbanos e da transmissão pela mídia. Acontecimento e mídia se encontram nessa forma de significar o espaço. Ao invés de marcos cívicos e históricos, o que se encontra aí são diversas manifestações populares, em sua diversidade: discurso da arte e da cultura. A multifuncionalidade dos espaços vazios condiciona a transitoriedade da vida nos grandes centros e a pluralidade de práticas, associadas a uma visão de mercado e de consumo, que determina a metaforização da multidão.

\section{AS PARCERIAS ENTRE PÚBLICO E PRIVADO}

Uma das condicionantes dos discursos das praças na atualidade está nas parecerias que se estabelecem entre o público e o privado. De um lado, o Estado e os governos estaduais e federais deixam de exercer a responsabilidade pelo planejamento das praças como um todo; de outro, são estabelecidas parcerias com o setor privado para as construções e reformas de praças. De um lado, o abandono (praças esvaziadas, medo de freqüentar as praças públicas, preferência por convívio em espaços fechados); de outro, a dependência da iniciativa privada junto ao público.

I. Lewkowikz et alii (2003) colocam que há um esgotamento do Estado na atualidade, com a passagem de uma sociedade de Estado para uma sociedade de Mercado (LEWKOWIKZ et alii). Assim, pensamos que o abandono e o vazio das praças, assim como a violência e a presença de moradores de rua e drogaditos, é um índice do esgotamento do Estado. Porém, embora a tese de Lewkowicz permita compreender uma série de fatos, compartilhamos aqui a perspectiva de Orlandi, segundo a qual, "o Estado, embora seja posto em situação de co-adjuvante, não tem realmente este papel. O Estado falha e significa por esta falha." (ORLANDI, 2010, p. 18). Uma das marcas da presença do Estado pela falha, a nosso ver, está na regulação das relações entre o público e o privado, que afeta os projetos de praça no espaço urbano, significando de certo modo as ausências do Estado. Isso abre a possibilidade de outras metáforas da sociedade, como as que envolvem a multidão consumidora, o turismo, as imagens das empresas, das comunidades, etc..

Tomemos duas iniciativas de parceria que fomentaram projetos de praça. No Estado de São Paulo, as parcerias entre prefeituras de várias cidades e a CPFL resultaram em algumas reformas. Nesse caso, o discurso é marcado pela repetição de slogans como "A CPFL abraçou a causa ambiental e adotou esta praça", que aparecem em algumas praças reformadas de São José do Rio Preto. O discurso ecológico e do voluntariado marca essa parceria que toma corpo no espaço público. As placas alocadas no interior das praças dirigem-se sobretudo aos que vêm a praça de fora, nas ruas, nos automóveis, e desse modo elas produzem uma visibilidade do lugar e da empresa. Frequentemente essas reformas estão associadas a projetos de iluminação, como em Botucatu, onde ocorreu o Projeto "Ilumina Botucatu" (PREFEITURA MUNICIPAL DE BOTUCATU, 2011), que contou 
com uma reforma e nova iluminação da Praça da Catedral. Os discursos da "segurança", da estética e da "valorização dos prédios históricos" fazem parte desses projetos.

Em Belo Horizonte, a Praça da Liberdade, localizada próxima à área central, foi restaurada e vem sendo mantida por meio de parcerias. Essa restauração faz parte de uma série de intervenções que levam à formação do "Circuito Cultural Praça da Liberdade":

\begin{abstract}
Um dos maiores complexos culturais integrados do país aberto ao público, o Circuito Cultural Praça da Liberdade, transformará os edifícios públicos do entorno da Praça da Liberdade em um conjunto de centros e atividades culturais com ênfase na contemporaneidade, interatividade e inclusão social pela ciência, história, cultura e artes. Além de assistir a apresentações e exposições artísticas e culturais, o público poderá freqüentar museus, centros de memórias, salas de espetáculos, participar de cursos, oficinas e atividades interativas. (SECRETARIA DE ESTADO DE CULTURA DE MINAS GERAIS, 2011)
\end{abstract}

O Circuito Cultural Praça da Liberdade envolve parcerias da Secretaria de Estado de Cultura de Minas Gerais com a iniciativa privada e com outras instituições públicas. Fazem parte do Circuito o Centro Cultural Banco do Brasil de Belo Horizonte, o Espaço do Conhecimento, em parceria com a TIM e UFMG; o Museu das Minas e do Metal, em parceria com a EBX; o Memorial de Minas Gerais, com patrocínio da Vale e o Centro de Arte Popular, da Cemig e alguns espaços públicos restaurados: o Palácio da Liberdade, a Biblioteca Pública Estadual Luiz de Bessa, o Arquivo Público Mineiro e o Museu Mineiro.

Seguindo a tendência já apontada de intervenções em áreas centrais, esse projeto aponta para uma passagem da praça cívica para a praça histórica e cultural, aliada ao ambiental. Note-se que o conjunto arquitetônico e paisagístico da Praça da Liberdade foi tombado em 1977 pelo IPHEA. Além disso, os prédios públicos que abrigavam instituições do governo de Minas Gerais foram transferidos para a "Cidade Administrativa", projetada por Oscar Niemeyer e inaugurada em 2010 na Zona Norte da cidade. O que antes estava distribuído em vários prédios da administração estadual foi integrado em 18 secretarias e 25 órgãos públicos na Cidade Administrativa. O discurso da gestão e da eficiência, juntamente com a construção sustentável marca essa transformação organizacional do espaço da cidade, prevendo-se o "desenvolvimento" do setor Norte, enquanto nas regiões centrais se constituem sítios históricos e culturais.

As adoções de praças são institucionalizadas em muitas prefeituras brasileiras. $\mathrm{Na}$ cidade de São Paulo elas foram instituídas em 1981 por meio do Programa "Adote uma Praça". As adoções podem ser efetuadas por pessoas jurídicas e subprefeituras, pessoas físicas, associações e agentes de promoção. Uma prática semelhante foi adotada em Campinas. Vejamos algumas das orientações que circulam em um jornal de São Paulo e em um site da Prefeitura de Campinas:

Desde 1981 a população paulistana pode contribuir na manutenção das áreas verdes da capital. Através do Programa Adote uma Praça é feito uma cooperação entre a iniciativa privada e o poder público para que as praças, jardins e canteiros sejam cuidados pela população com o apoio da prefeitura. O objetivo da parceria é manter os espaços sempre em ordem, garantindo a beleza paisagística e a qualidade de vida da comunidade local. Atualmente existem cerca de 642 áreas verdes adotadas em São Paulo, e outras 90 estão em processo de adoção. (DIMENSTEIN, 2011) A Prefeitura de Campinas permite a adoção de praças em todo o território campineiro. Essa atitude pode ser tomada por empresas e instituições, de preferência que se localizem no mesmo bairro 
onde a praça está instalada. A empresa que adota uma praça pode divulgar sua logomarca em uma placa a ser instalada no gramado da praça adotada. Assim, a empresa pratica uma ação de cidadania e, ao mesmo tempo, tem a oportunidade de divulgar sua marca. Ao adotar uma praça, a empresa a mantém em boas condições, cuida de sua preservação, a partir de cuidados diários simples, como disponibilização de lixeiras para descarte de lixos e cuidados com sua manutenção, como plantar novas árvores e solicitar a poda, sempre que necessário, ao Departamento de Parques e Jardins. (PREFEITURA MUNICIPAL DE CAMPINAS, 2011)

Diante dessas novas condições, praças são adotadas por empresas, por escolas, por moradores, por condomínios, por associações de bairro, etc. Tais práticas deixam traços nas materialidades textuais das praças, com a inserção de placas, de objetos, de equipamentos simbolizados pelas parcerias entre público e privado. São produzidas, assim, imagens das empresas e das instituições que participam das reformas e manutenções das praças, geralmente acompanhadas da discursividade ecológica.

\section{PRAÇAS, COMUNIDADES, IDENTIDADES}

Uma outra forma de imaginário construída pelos discursos das praças é o de comunidades específicas, de modo que a fragmentação do urbano, a pluralidade de grupos sociais, ganha corpo no espaço público. Nessas situações, nota-se a apropriação de discursos de grupos sociais pelos poderes públicos, de modo a se trabalhar as identidades comunitárias, organizando-as na relação com as instituições públicas e privadas. Como afirma Orlandi, a "identidade resulta de um processo" (ORLANDI, p. 11), ela tem historicidade e faz movimentar a memória. Organizar as identidades com mediação do poder público e participação do privado implica em migrações de sentido, e com isso, em outras formas de identificação que ganham corpo no espaço público

Tomemos o caso da praça Moysés Miguel Haddad, no bairro da Boa Vista, em São José do Rio Preto, onde se percebe um imaginário artístico ligado ao movimento Hip Hop. Com a reforma da praça ("revitalização") foram inseridos vários grafites em muros e outros objetos da praça. Participaram dessa reforma, além da Secretaria Municipal de Serviços, grafiteiros, participantes do movimento Hip Hop e da Casa do Hip Hop, e agentes do Programa Municipal DST-Aids. A materialidade da praça, que também conta com um pequeno espaço de apresentações, é marcada pela apropriação pelo poder público do discurso dos grafiteiros, ao mesmo tempo em que fica significada a recusa das manifestações de pichação, como se vê nesta fala de um dos organizadores de um evento realizado na praça, Glauco da Silva Garcia: "Além de conscientizar a população, a grafitagem substitui a pichação por expressões artísticas" (DIARIOWEB, 2011). Junto aos grafites, alguns escritos assinalam as parcerias da prefeitura com movimentos sociais, projetos assistenciais e empresários (como os de comércio de tintas).

Observe-se que, em 25 de maio de 2011, a presidente Dilma Roussef sancionou uma lei (lei 12.408), que descriminaliza o ato de grafitar, desde que consentido pelo proprietário. Assim, de um lado a pichação é coibida, considerada crime, e de outro a grafitagem passa a ser admitida sob certas condições. E enquanto a praça pública abriga o grafite, no mesmo gesto são excluídos imaginariamente, no discurso jurídico, os pichadores. Observe-se que, não obstante, a praça Haddad é marcada por pichações em alguns dos muros, nos 
equipamentos do ponto de ônibus e outros locais, o que indica a resistência dos sujeitos e sua inserção política no espaço público.

A comunidade dos idosos também se faz presente em intervenções nas praças. Recentemente, equipamentos de ginástica para idosos têm sido instalados em várias praças e parques, direcionados para esses sujeitos. Outra iniciativa nesse sentido está na inauguração de praças para os aposentados, como ocorreu na cidade de Avaré (SP) onde foi construído um espaço coberto com mesas para jogos de tabuleiro. A placa de inauguração traz a nomeação da praça: "Centro de Convivência para Aposentados".

Entendemos que essas delimitações dos espaços da praça, e de seu público frequentador, participam até certa medida do que Orlandi tem chamado de formação de "comunidades segundas", ou seja, comunidades que reúnem grupos sociais, para além daquelas que se formam em instituições como a família e a escola:

\footnotetext{
Daí a necessidade de, além da comunidade de fato (família, Igreja, empresa, nação etc), estabelecermos comunidades segundas (as que temos vontade de eleger, em que nossos desejos podem ser satisfeitos). É para elas que se dirige nosso imaginário. Essas comunidades segundas são grupos em que cada um pode desempenhar seu desejo de reconhecimento como o reconhecimento de seu desejo e de seu ser. (ORLANDI, 2006, p. 23).
}

No caso da construção de praças que incorporam as comunidades segundas, como a dos grafiteiros, dos idosos, etc., ocorre um deslocamento de sentido, na medida em que se dá uma institucionalização dessas comunidades. Se, de um lado, tais praças visam a contemplar a diversidade social, de outro elas produzem uma homogeneidade local com a concentração do mesmo. A legitimação das comunidades segundas pelo poder público produz no mesmo gesto de reconhecê-las, uma forma de controle social, pois elas são afastadas da possibilidade de certas significações históricas ou conflituosas, com base em um discurso consensual que evita as contradições e o imaginário transgressor desses grupos.

\section{CONCLUSÃO}

As praças na contemporaneidade não resultam de uma orientação geral de planejamento, mas sim de diferentes projetos que produzem certos imaginários no espaço público. A concentração de sujeitos urbanos coloca a questão da quantidade, que nos projetos de praça tem sido metaforizada como "multidão" e pelo "vazio". Ao mesmo tempo, a fragmentação da sociedade é uma das marcas da contemporaneidade e leva à produção de identidades em grupos, instituições, empresas, comunidades com suas simbologias. Há também a busca de uma unidade por meio de uma origem histórica comum, institucionalizada. Assim, consideramos o complexo de praças em suas relações de diferença, de complementaridade, de contradição, etc.

Observamos que o discurso de organização das praças, de implantação de projetos, de intervenções no espaço público, está ligado ao modo de o Estado se apresentar na atualidade. As parcerias público-privado produzem uma divisão no espaço da cidade, na medida em que o Estado, e por conseguinte os estados e os municípios, colocam em jogo a participação da iniciativa privada nos projetos e na manutenção de praças. O que ocorre 
não é somente uma fragmentação do espaço e dos sujeitos, mas sim um modo de organização das formações sociais existentes nos espaços citadinos, na tensão entre a multidão e os imaginários históricos, empresariais e comunitários.

A multidão aparece aí como uma forma do imaginário coletivo contemporâneo. Uma multidão de sujeitos, que se ajuntam sem deixar de exercer a individualidade, compondo um mosaico de cores, de escritos, de signos corporais, etc. A praça seca é um sintoma dessa multidão que só é possível enquanto acontecimento: é a praça-acontecimento. A multidão não deixa seus traços no espaço: o grafismo formal mínimo elide a possibilidade de identificação específica. O espaço ritual da contemporaneidade é minimalista, clean, iluminado, amplo, mediático. Divisão espacial necessária para comportar a pluralidade, sem se filiar aos imaginários identitários que compõem de outro lugar essa pluralidade. Para haver multidão é preciso deslocamento e acontecimento. A multidão faz esquecer imaginariamente as formações sociais, as classes, as identidades comunitárias, demandando um lugar que a abrigue.

Enquanto na praça seca se reúnem as multidões, as praças comunitárias abrigam a fragmentação social, e aí uma série de materiais, imagens e símbolos enquadram o públicofrequentador. A praça comunitária é a contraparte da praça seca. Nela não se instala a multidão, mas sim a diversidade, distribuída em vários pontos da trama urbana, dis-postos segundo a organização que distingue a quantidade da diversidade.

Para se compreender tal disposição espacial na cidade, operamos com o conceito de "tópica cívica", de E. Orlandi:

Partimos da projeção de lugares institucionais como lugares discursivos - de produção de sentidos e de processos de identificação de sujeitos - para pensarmos o que chamamos de "tópica cívica": não há cidadania em abstrato, sobretudo se pensarmos as atuais formas de relação do Estado (ou a sua falta de relação) com os sujeitos histórico-sociais. O que há são sítios, lugares de definição, com sua materialidade, em que se configuram processos de manifestação concreta de sentidos de cidadania que não podem ser pensados fora das condições materiais de existência desses indivíduos (sujeitos individuados) na suas relações com a sociedade. (ORLANDI, 2010, p. 14)

Com essa concepção de uma tópica cívica, entendemos que a cidadania no espaço público, particularmente nas praças, não se restringe a uma identidade jurídica, ao modo abstrato, sem relação com o espaço e o tempo discursivos; ela se constitui na relação do Estado com os sujeitos histórico-sociais em determinados sítios de significação com suas materialidades específicas. Assim, a multidão (consumo), a história (turismo) e as identidades institucionais (públicas e privadas) e comunitárias (comunidades segundas) são formas imaginárias que resultam de processos de identificação, que envolvem regiões centrais e seus entornos, bairros, periferias, amplos espaços e outros. A tópica cívica, na conjuntura atual, se estabelece por meio de uma relação entre público e privado, enquanto modo de agenciamento pelo Estado das formações sociais no espaço público.

\section{REFERÊNCIAS BIBLIOGRÁFICAS}

CASTILHO, A.; VARGAS, H. C.; L. H. (2009). Intervenções em Centros Urbanos: objetivos, estratégias e resultados. $2^{\mathrm{a}}$ ed. Barueri: Manole. 
DIARIOWEB. http://www.diarioweb.com.br/editorial. Acesso em 16/08/2011.

DIMENSTEIN, G. Folha Online. http://www1.folha.uol.com.br/folha/dimenstein/ noticias/gd200906d.htm). Acesso em 16/08/11.

FERRARI, C. (2004). Dicionário de Urbanismo. São Paulo: Disal.

FERREIRA, Aurélio Buarque de Holanda. (1999). Novo Aurélio Século XXI: o dicionário da língua portuguesa / Aurélio Buarque de Holanda Ferreira. $3^{\mathrm{a}}$ ed. totalmente revista e ampliada. Rio de Janeiro: Nova Fronteira.

FILHO, A. C. (2008). Praça XV: projetos do espaço público. Rio de Janeiro: 7Letras.

LEWKOWICZ et alii. (2003). Do fragmento à situação - anotações sobre a subjetividade contemporânea. Buenos Aires: Editora Altamira.

MACHADO, J. (2010). Comunicação e Cidades Patrimônio Mundial no Brasil. Brasília: UNESCO, IPHAN.

NUNES, J. H. (2006a). Escrita e subjetivação na cidade. In: B. Mariani (Org.). A escrita e os escritos. São Carlos: Claraluz, p.45-58.

. (2006b). O sujeito no discurso: um lugar para falar na praça. In: Marchezan, R.C.; Cortina, A.. (Org.). Os fatos da linguagem: esse conjunto heteróclito. 1 ed. Araraquara: FCL-UNESO Laboratório Editorial, v. 10 , p. 21-38.

ORLANDI, E. (2001). Cidade atravessada: os sentidos públicos no espaço urbano. Campinas: Pontes. . (2006). À flor da pele: indivíduo e sociedade. In: A Escrita e os Escritos: reflexões em análise do discurso e em psicanálise. B. Mariani (Org.). São Carlos: Claraluz. . (2010). Discurso e Políticas Públicas Urbanas: a fabricação do consenso. Campinas: Editora RG. . (2011). Discurso, Espaço, Memória.- caminhos da identidade no Sul de Minas. Campinas: Editora RG.

PREFEITURA MUNICIPAL DE BOTUCATU. http://www.botucatu.sp.gov.br/. Acesso em 16/08/2011.

PREFEITURA MUNICIPAL DE CAMPINAS.http://www.campinas.sp.gov.br/governo/ servicos-publicos/dpj/ gauc.php. Acesso em 16/08/11.

ROBBA, F. (2003). Praças Brasileiras. $2^{\mathrm{a}}$ ed. São Paulo: EDUSP: Imprensa Oficial do Estado de São Paulo.

SECRETARIA DE ESTADO DE CULTURA DE MINAS GERAIS. http://www.cultura.mg.gov.br/. Acesso em 16/08/11. 